\section{EAGE/SEG Research Workshop 2017 \\ Results of a baseline magnetometric resistivity survey at the Field Research Station, Alberta}

\section{Geophysical Monitoring of $\mathrm{CO}_{2}$ Injection - CCS and CO2-EOR}

\author{
B. Giroux ${ }^{1}$, A. Bouchedda 1 , A. Saeedfar 2 , D. Lawton ${ }^{3}$ \\ 1 Institut National de la Recherche Scientifique \\ 2 CMC Research Institutes \\ 3 University of Calgary
}

INRS

UNIVERSITÉ DE RECHERCHE

\section{Introduction}

In saline aquifers, the large conductivity contrast between $\mathrm{CO}_{2}$ and brine makes electrical properties appealing for monitoring $\mathrm{CO}_{2}$ plume progres subject to technical difficulties due to challenges in the instletion ase maintenance of pertates are weak in conductive media, and measurements in saline aquifers cal be very noisy (Schmidt-Hattenberger et al., 2011).

With the magnetometric resistivity method (MMR), electrical property contrasts in the ground are obtained from the measure of the magnetic field induced by a galvanic source (Edwards and Nabighian, 1991). Due to the fact that the measurements are done with a magnetic sensor, MMR offers many advantages for monitoring: easier deployment in boreholes (no contact needed) and problems related to electrode installation and corrosion are avoided. Also, the problem of noise in conductive media is reduced because the measured signal is a function of current density and not conductivity.

The Field Research Station (FRS) is an experimental site operated by the Containment and Monitoring Institute of Carbon Management Canada. A controlled $\mathrm{CO}_{2}$ release experiment is planned a this site for the next 5 years, to test the monitoring capability of various geophysical method (Lawton and Osadetz, 2014; Lawton, 2016). A preliminary numerical study Plo the plume at the FRS, given adequate noise conditions (Bouchedda and
Giroux, 2015).

In this contribution, we present the results of a baseline survey conducted at the FRS. The aim of the survey was to evaluate the noise conditions a the site and determine the optimal data acquisition parameters, in addition this experiment is the first field application of $\mathrm{MMR}$ for $\mathrm{CO}_{2}$ monitoring.

\section{Survey parameters}

The Field Research Station covers an area of $1 \mathrm{~km} \times 1 \mathrm{~km}$ located in the county of Newell, Southwest of Brooks, Alberta. The FRS site encompasses Upper Cretaceous clastic reservoir formations. A 3D seismic survey show that geology at the site is mostly $1 \mathrm{D}$.

The MMR survey was performed June 20th to 23rd 2016. The acquisition equipment was composed of:

- a GGT-30 transmitter powered by a Hatz diesel motor generator (Zonge International, USA),

- a Zonge controller (Zonge International, USA)

(Zneceiver from GDD instrumentation Inc. (Canada);

- a MAG43-3D fluxgate borehole probe and preamplifier from Geonics Ltd. (Canada);

- electrodes made of reinforcing steel bars approximately $1.8 \mathrm{~m}$ long.

Two sets of measurements were done using two orthogonal current dipoles (Figure 2). Acquisition parameters are:

- current at dipole 1 consists of $100 \%$ duty cycle current at $4 \mathrm{~Hz}$. - for dipole 2, 50\% duty cycle current at $2 \mathrm{~Hz}$ repetition was used. - the GGT-30 transmitter allowed injecting between $25 \mathrm{~A}$ and $30 \mathrm{~A}$ - measurements were carried out in the observation well \#2 located approximately $30 \mathrm{~m}$ northeast of the injection well, from $100 \mathrm{~m}$ down to $325 \mathrm{~m}$ depth (fiberglass casing is in place within the measurement interval). - measurements were performed every $2 \mathrm{~m}$ near the reservoir (about 300 $m$ deep), but the step size was increased above and below. - time-series long enough to hold 512 cycles were recorded for dipole

and 256 cycles for dipole 2 .

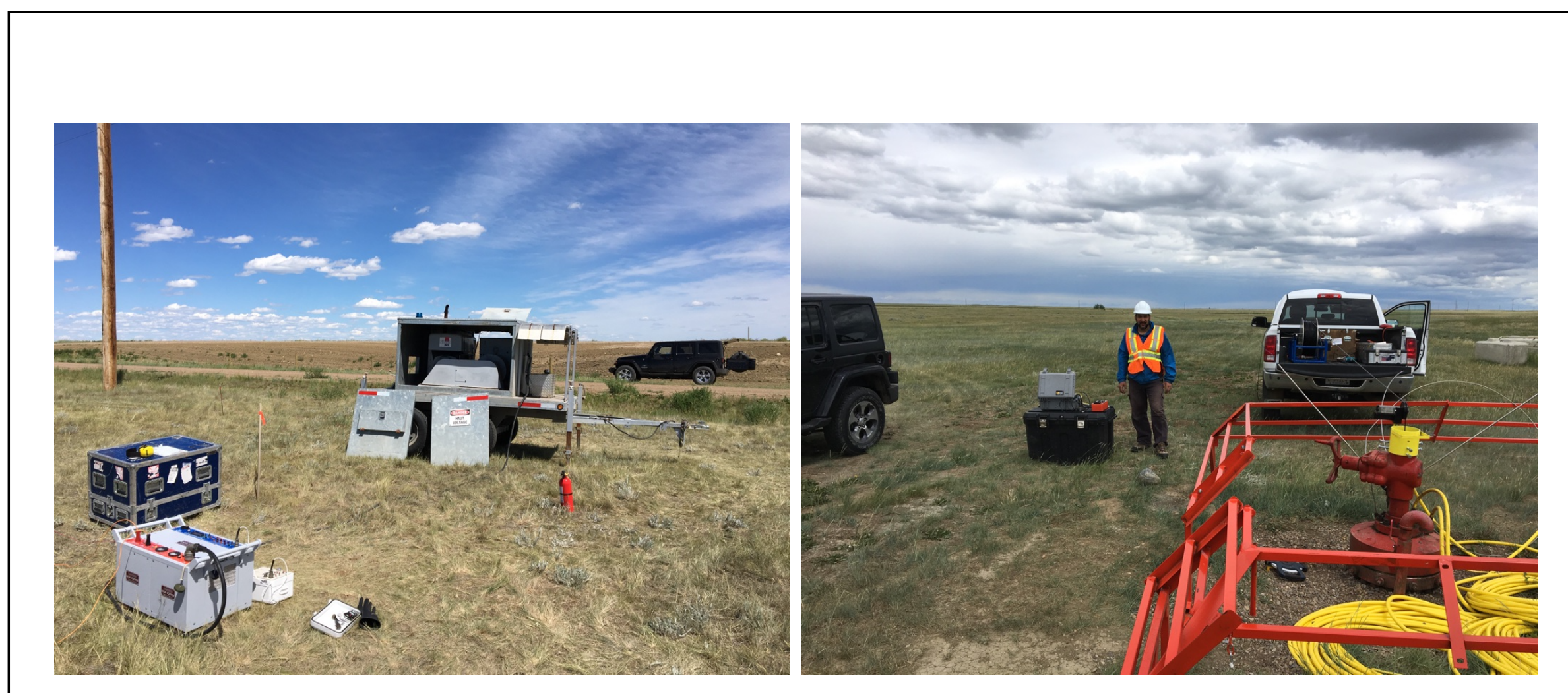

Figure 1 - Field equipment deployed at the FRS.

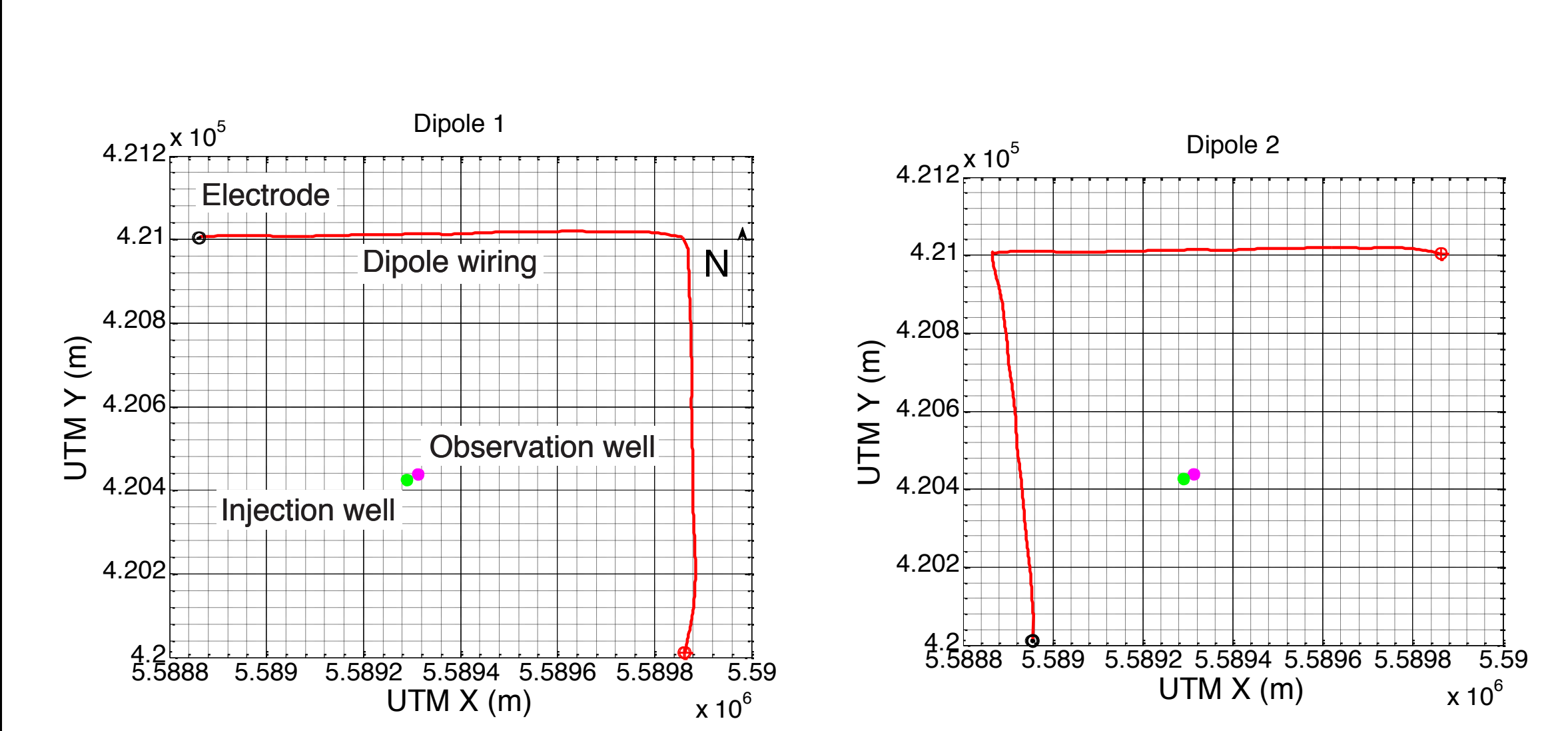

Figure 2 - Location of injection dipoles.

\section{Survey results}

A four-step processing sequence was applied to the data before interpretation. Detrending was first achieved by eliminating low frequency noise was the terrestrial magnetic field. The sign wigh thequench to after stacking. Third the $x$ and $y$ conponts of the signal we depo 2 using the primary field and orthogonal Procrustes rotation analysis as described by Key and Lockwood (2010). Finally, the primary magnetic field caused by the dipole wires was calculated analytically knowing wire and receiver positions, and subtracted from the measurements.

MMR magnetic field data after processing are shown in Figure 4. Theoretically, the $B_{z}$ field for a layered earth is zero (Acosta and Worthington, 1983). However, a linear trend can be observed in this component. This trend is attributed to inaccuracies in the observation well position and the effect of metallic pipelines and well casings that are far from the receiver (see Figure 5). Indeed, metallic pipelines create a long wavelength anomaly that appears as linear trends. This effect should be removed in time-lapse measurements by taking the difference between the baseline measurements and the measurements after $\mathrm{CO}_{2}$ injection. On the contrary, the horzontal components show a few local anomalies that can be explained by layering effect or variation of resistivity with depth.

A series of measurements were done at a depth of $320 \mathrm{~m}$ with the transmitter off to evaluate the noise level at the site (Figure 6). Time series segments were stacked to evaluate the noise level for conditions comparable to the
processed data. The values of noise level after stacking are low, with 2 pT and $6 \mathrm{pT}$ for dipole 1 and dipole 2 respectively.
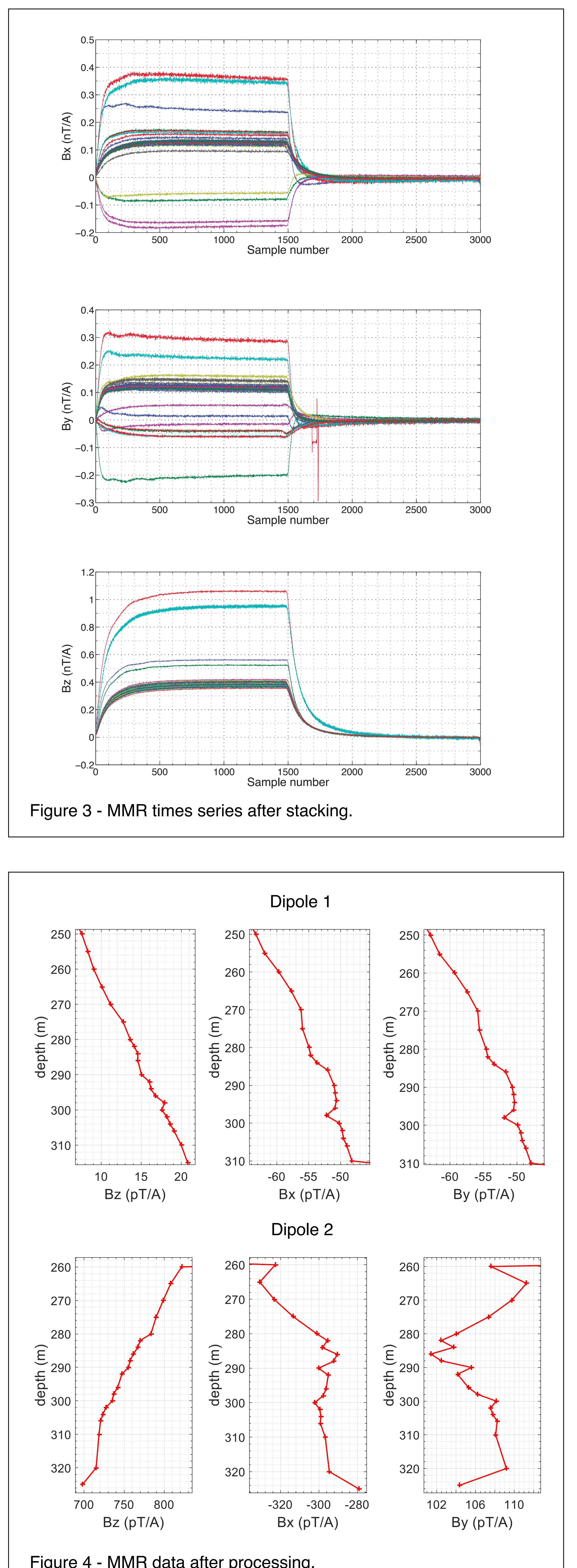

Conclusion

Downhole MMR measurements were performed at the Field Research Station in Alberta to evaluate the suitability of the method to monitor injected $\mathrm{CO}_{2}$ movements under real conditions. Low contact impedance at the source electrodes allowed injecting high current ( $25 \mathrm{~A}$ to $30 \mathrm{~A}$ ), yielding low signal- to-noise ratio. Baseline data of high quality were thus obtained using the two orthogonal source dipoles.

Basic modeling indicate that a $5 \mathrm{~m}$ thick disc of radius larger than $15 \mathrm{~m}$ centered at the injection well and with a resistivity 10 times higher than the host rocks, produces an anomaly larger than $10 \mathrm{pT}$, which would be detectable given conditions comparable to the baseline survey. In order to bette assess the amplitude of the MMR anomalies, $\mathrm{CO}_{2}$ flow modeling will be used to estimate its spatial distribution and to model more realistic changes in resistivity. This exercice will allow evaluating the resolving power of MMR data inversion. The contribution of MMR data in joint inversion schemes (especially MMR-ERT) will also be assessed.

Nevertheless, questions remain relative to time-lapse repeatability conditions and true amplitude of the anomalies that will be generated by the injected $\mathrm{CO}_{2}$, which will be answered by a repeat survey that will be conducted after start of injection

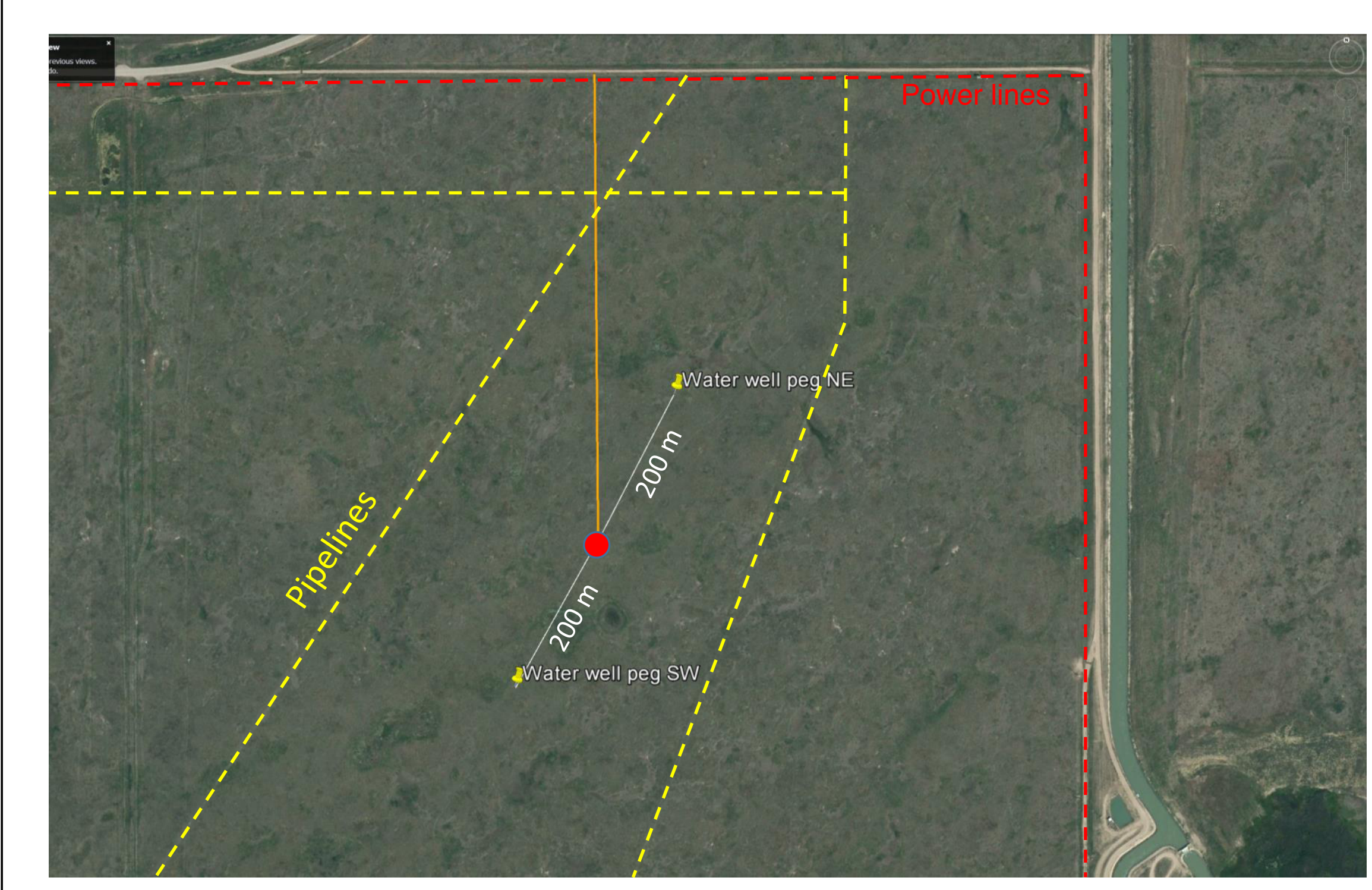

Figure 5 - Aerial photo showing the location of pipelines and power lines at the FRS.

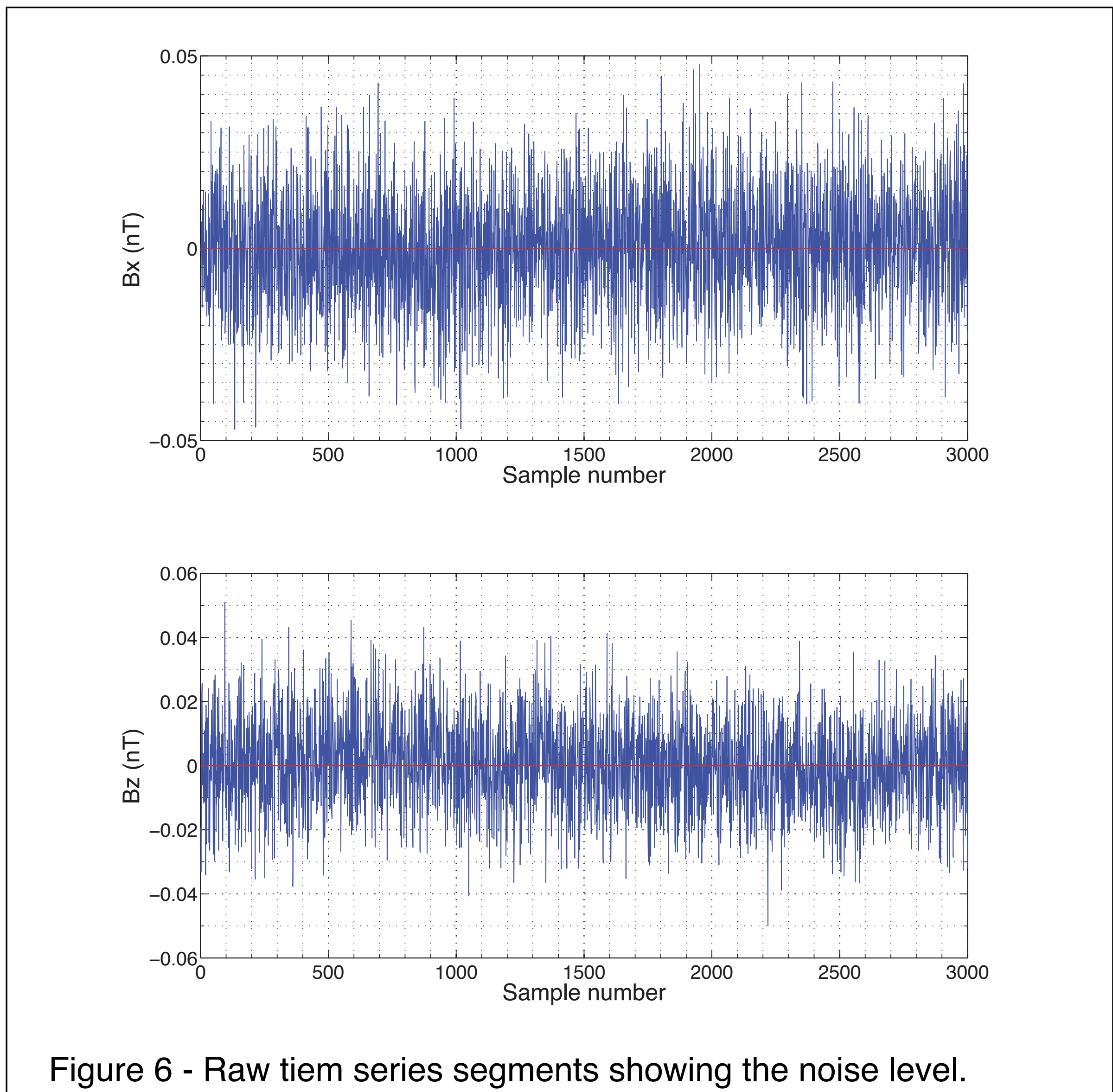

Acknowledgements

This work was supported by CMC Research Institutes Inc., grant C394 to B. Giroux

References

- Acosta, J.E. and Worthington, M.H. [1983] A borehole magnetometric resistivity experiments. Geo- physical Prospecting, 31(5), 800-809. - Bouchedda, A. and Giroux, B. [2015] Synthetic Study of CO2 monitoring using Time-lapse Down-hole Magnetometric Resistivity at Field Reseach Station Alberta, Canada. In: SEC Technical Program Expanded Abstracts 2015. 5529-5533.

- Edwards, R.N and Nabighian, M.N. [1991] The magnetometric resistivity method. In: Nabighian $\mathrm{MN}$ (Ed) Electromagnetic Methods in Applied Geophysics, Investigations in Geophysics, 2 Application, chap. 2 SEG, 47-104.

作 CSEM receivers using orthog- onal Procrustes rotation analysis. GeophySics, 75(3), F63-F70.

Lawton, D.C. [2016] The CaMI Field Research Station: Shallow CO2 release monitoring. IEAGHG modelling and monitoring research workshop, Edinburgh, Scotland.

Cowton, D.C. and Osadetz, K. [2014] Monitoring Conformance and Containment for Geological Carbon Storage: Can Technology Meet Policy and Public Requirements? AGU Fall Meeting Abstracts.

- Schmidt-Hattenberger, C., Bergmann, P., Kiessling, D., Krüger, K Rücker, C., Schüt, H. and Group, K. [2011] Application of a Vertical Electrical Resistivity Array (VERA) for monitoring CO2 migration at the Ketzi 